\title{
Vancomycin dosing in low-flux hemodialysis; is adjustment of drug dosage necessary?
}

\author{
Niloofar Khodabandehloo $^{1}$, Arash Fourodi ${ }^{1}$, Aria Jenabi ${ }^{*}{ }^{*}$ \\ ${ }^{1}$ Department of Internal Medicine, Rasoul Akram Hospital, Iran University of Medical sciences, Tehran, Iran \\ ${ }^{2}$ Department of Nephrology, Dialysis Center, Rasoul Akram Hospital, Iran University of Medical sciences, Tehran, Iran
}

\section{A R T I C L E IN F O}

\section{Article Type:}

Original

\section{Article History:}

Received: 8 June 2018

Accepted: 19 September 2018

Published online: 29 October 2018

\section{Keywords:}

Vancomycin

Hemodialysis

Renal failure

Drug toxicity

\begin{abstract}
A B S T R A C T
Introduction: Vancomycin is a wide useable antibiotic against gram-positive bacteria species in different clinical setting particularly in hemodialysis patients.

Objectives: The present study aimed to assess the serum level of vancomycin before and after hemodialysis.

Patients and Methods: This cross-sectional study was performed on patients who were hospitalized and medicated by vancomycin with the loading dose of $1000 \mathrm{mg}$ followed by the maintenance dose of $500 \mathrm{mg}$ after each dialysis session every other day. All patients were dialyzed with a low-flux dialyzer membrane. Half an hour before and immediately after dialysis, $2 \mathrm{~mL}$ blood sample was taken and stored at $-20^{\circ} \mathrm{C}$ until assaying the level of vancomycin.

Results: The average reduction in the serum level of vancomycin was totally $17.65 \pm 1.69 \%$. The mean reduction in the serum level of vancomycin was significantly higher in the patients aged higher than 60 years, as compared to other ones. But the level of drug was independent to gender or body mass index.

Conclusion: Using low-flux dialyzer membranes, the average reduction in the serum level of vancomycin is expected to be in the range of $12.43 \%$ to $21.56 \%$ that age was directly associated with the average reduction of the level of vancomycin. Therefore, adjusting and monitoring the serum level of drug in old ages even in the cases of using low-flux dialyzer membranes is recommended.
\end{abstract}

\section{Implication for health policy/practice/research/medical education:}

Given results of our study on assessing the serum level of vancomycin (the loading dose of $1000 \mathrm{mg}$ followed by the maintenance dose of $500 \mathrm{mg}$ ) before and after hemodialysis, it is recommended to adjust and monitor the serum level of drug in old ages even in the cases of using low-flux dialyzer membranes.

Please cite this paper as: Khodabandehloo N, Fourodi A, Jenabi A. Vancomycin dosing in low-flux hemodialysis; is adjustment of drug dosage necessary? J Renal Inj Prev. 2019;8(2):112-115. DOI: 10.15171/jrip.2019.21.

\section{Introduction}

Vancomycin is a wide usable antibiotic against grampositive bacteria species in different clinical setting particularly in hemodialysis patients (1). In fact, because of high incidence of stenting-related bacterial infections, following vascular accessing, vancomycin is widely administered in hemodialysis patients. This antibiotic is excreted by kidneys and thus its renal clearance as well as its therapeutic plasma level should be monitored accurately. Therefore, plasma level of this drug should be monitored in patients who candidate for hemodialysis especially in those who receive high-flux hemodialysis
(2-7). According to the common clinical approaches, this drug should be administered with a loading dose of $1 \mathrm{~g}$ following dialysis or within the last hour of each session of dialysis, followed by administrating maintenance dose of the drug in the range of $0.5 \mathrm{~g}$ to $1.0 \mathrm{~g}$ after dialysis $(5,7)$. To this approach, the level of vancomycin is maintained between $5-20 \mu \mathrm{g} / \mathrm{mL}$ in most of the patients. However, it may be leveled lower than $10 \mu \mathrm{g} / \mathrm{mL}$ in about $30 \%$ to $40 \%$ may leading antibiotic treatment failure $(8,9)$. It can causally occur on highly permeable dialysis membranes that results in the high clearance value in these patients. In such situations, therapeutic and non-toxic vancomycin 
levels were recommended to be obtained by giving 1000 $\mathrm{mg}$ of vancomycin, intravenously, as a loading dosage and $500 \mathrm{mg}$ during every subsequent dialysis to achieve optimal drug efficacy as well as appropriate drug clearance (10). Moreover increasing cumulative dosages of the drug in those patients with renal insufficiency due to the failure of renal clearing process in nephrotoxicity may be predictable, leading high drug toxicity rate (11).

\section{Objectives}

The present study aimed to assess the serum level of vancomycin before and after hemodialysis. In other words, we aimed to determine the therapeutic dose of the drug and its main determinants in patients undergoing hemodialysis.

\section{Patients and Methods \\ Study patient}

This cross-sectional study was conducted at dialysis ward in Rasoul Akram hospital, between April and December 2015 , on patients who were hospitalized and medicated by vancomycin with the loading dose of $1000 \mathrm{mg}$ followed by the maintenance dose of $500 \mathrm{mg}$ after each dialysis session every other day.

All patients in our study aged higher than 18 years who suffered end-stage renal disease requiring hemodialysis three times a week (every session for 3.5 to 4.0 hours). The subjects received vancomycin therapy due to prophylaxis protocol or to definitive diagnosis of bacterial infection. Dialysis was performed for them with a filter of a $1.3 \mathrm{~m}^{2}$ surface area by low-flux dialyzer membrane (PS13 LF, Meditechsys Co, Tehran, Iran). The baseline characteristics including demographics, body mass index (BMI), underlying disorders led to end-stage renal disease (diabetes mellitus, hypertension, or other diseases), drug history, the time of receiving vancomycin, and blood access of dialysis (catheter or fistula) were extracted from hospital files and entered into the study checklists. Half an hour before and immediately after dialysis, $2 \mathrm{~mL}$ blood sample was taken and stored at $-20^{\circ} \mathrm{C}$ until assaying the level of vancomycin. According to the protocols, the therapeutic range of vancomycin was considered to be 10 $20 \mathrm{mg} / \mathrm{L}$.

\section{Ethical issues}

This study was approved by the ethics committee of Iran University of Medical Sciences. Informed consent was obtained from all patients or their families. Human rights were respected in accordance with the Helsinki Declaration.

\section{Statistical analysis}

Results were presented as mean \pm standard deviation (SD) for quantitative variables and were summarized by absolute frequencies and percentages for categorical variables. Normality of data was analyzed using the KolmogorovSmirnoff test. Categorical variables were compared using chi-square test or Fisher's exact test when more than 20\% of cells with expected count of less than 5 were observed. Quantitative variables were also compared with $t$ test or Mann-Whitney U test. For the statistical analysis, the statistical software SPSS version 16.0 for Windows (SPSS Inc., Chicago, IL) was used and $P$ values of 0.05 or less were considered statistically significant.

Results

In total, 55 patients (33 men and 22 women) were assessed. Of those, $70.9 \%$ aged higher than 60 years and $7.2 \%$ were obese $\left(\mathrm{BMI}>30 \mathrm{~kg} / \mathrm{m}^{2}\right)$. Regarding underlying disorders leading end-stage renal disease, $20 \%$ suffered diabetes mellitus type II, $38.0 \%$ were hypertensive, and $42.0 \%$ suffered other diseases. Overall, $78.2 \%$ suffered from chronic kidney disease undergoing chronic hemodialysis. Regarding dose of vancomycin, 9.1\% received the first dose, $12.7 \%$ received the second dose, $65.4 \%$ received the third dose, and $12.7 \%$ received the fourth dose of vancomycin. Of 55 patients assessed in the present survey, $16.4 \%$ had fistula and $83.6 \%$ had catheter as vascular access (Table 1).

The average reduction in the serum level of vancomycin was totally $17.65 \pm 1.69 \%$ (ranged $12.43 \%$ to $21.56 \%$ ) $\mu \mathrm{g} / \mathrm{mL}$ (Table 2). There was no difference in the average reduction in the level of vancomycin between men and women $(17.86 \%$ versus $17.33 \%, P=0.256)$. However it was significantly higher in patients older than 60 years compared to younger ones $(17.95 \%$ versus $16.90 \%, P$

Table 1. Baseline characteristics of study population

\begin{tabular}{|c|c|}
\hline Variable & No. (\%) \\
\hline \multicolumn{2}{|l|}{ Gender } \\
\hline Male & $33(60.0)$ \\
\hline Female & $22(40.0)$ \\
\hline \multicolumn{2}{|l|}{ Age (y) } \\
\hline$>60$ & 39 (70.9) \\
\hline$<60$ & $16(29.1)$ \\
\hline \multicolumn{2}{|l|}{$\mathrm{BMI}\left(\mathrm{g} / \mathrm{m}^{2}\right)$} \\
\hline$>30$ & $4(7.27)$ \\
\hline$<30$ & $51(92.72)$ \\
\hline \multicolumn{2}{|l|}{ Underlying disease } \\
\hline Diabetes mellitus & $11(20.0)$ \\
\hline Hypertension & $20(38.0)$ \\
\hline Others & $24(42.0)$ \\
\hline \multicolumn{2}{|l|}{ Type of kidney injury } \\
\hline Chronic & $43(78.2)$ \\
\hline Acute & $12(21.8)$ \\
\hline Receiving nephrotoxic drugs & $6(10.9)$ \\
\hline \multicolumn{2}{|l|}{ Dose of vancomycin } \\
\hline First & $5(9.10)$ \\
\hline Second & $7(12.72)$ \\
\hline Third & $36(65.45)$ \\
\hline Forth & $7(12.72)$ \\
\hline \multicolumn{2}{|l|}{ Vascular access } \\
\hline Fistula & $9(16.36)$ \\
\hline Catheter & $46(83.64)$ \\
\hline
\end{tabular}

Abbreviation: BMI, Body mass index. 
$=0.035)$. Also, no difference was revealed in the mean reduction of the level of drug between obese and nonobese patients $(17.76 \%$ versus $17.64 \%, P=0.891)$ (Table $3)$. Of 55 patients assessed in the study, the post-dialysis serum level of vancomycin maintained at the therapeutic range $(10-20 \mu \mathrm{g} / \mathrm{mL})$ in 53 patients $(96.4 \%)$; thus, adjusting the dose of the drug was required for only in $3.6 \%$.

\section{Discussion}

According to the literature, the most important factor affecting the reduction of the level of vancomycin in hemodialysis patients was the type of dialysis membrane that the use of high-flux membranes might lead to an average reduction of $35 \%$ to $50 \%$ in the level of vancomycin (12). Thus, adjustment of drug dosage is essential to avoid antimicrobial treatment failure. In contrast, the average reduction of the level of vancomycin in low-flux membranes was shown to be about $17 \%$ without need to following an especial protocol for adjusting drug dosage (13). According to our survey - which is used low flux the average reduction in the serum level of vancomycin was revealed to be $17.6 \%$ that was comparable with the previous reports, indicating no need to adjust the dose of vancomycin during dialysis with low-flux membrane. More important, of baseline variables, only age was directly associated with average reduction of the level of vancomycin as reducing in the level of the drug in the serum increases in the patients older than 60 years compared to the younger ones; consequently, there is a need for controlling titration of the drug dosages, even after using low-flux dialysis membranes in these patients. On the other hand, the reduction of the level of the drug was completely independent to gender or BMI.

Table 2. The mean percent reduction in serum level of vancomycin before and after dialysis in the patients, using low-flux polysulfone membranes 13

\begin{tabular}{ll}
\hline Average & 17.6515 \\
Mean & 17.79 \\
Standard deviation & 1.69 \\
Minimum & 12.43 \\
\hline Maximum & 21.56 \\
\hline
\end{tabular}

Table 3. The average reduction in the serum level of vancomycin $(\mu \mathrm{g} /$ $\mathrm{mL})$

\begin{tabular}{lll}
\hline & Average Reduction & $P$ value \\
\hline Gender & & \\
Male & 17.86 & 0.256 \\
Female & 17.33 & \\
Age (y) & & \\
$>60$ & 17.95 & 0.035 \\
$<60$ & 16.90 & \\
BMI (g/m $/ \mathrm{m}^{2)}$ & & \\
$>30$ & 17.76 & 0.891 \\
$<30$ & 17.64 & \\
\hline
\end{tabular}

Abbreviation: BMI, Body mass index.
In total, it seems that using a vancomycin dosing nomogram in conditions which high-flux membranes are used or in old patients who were planned to use low-flux membranes, can significantly improve and accelerate the achievement of the target trough concentrations (14). As a rule, vancomycin is not significantly dialyzable when hemodialysis is performed using a low flux membrane, while vancomycin is dialyzable when hemodialysis is performed using a high flux membrane (15). However, except for the potential effects of type of the membrane, other probable confounding factors should be considered. Based on the results of our study, older age was the main factor that affects the clearance of vancomycin. As indicated in previous studies, preexisting renal impairment and concomitant therapy with other nephrotoxic should be also considered as potential confounders that may affect the efficacy of drug in dialysis patients. For instance, as shown in the literature, the accepted incidence of nephrotoxicity secondary to vancomycin monotherapy is $<5 \%$ but increases to $43 \%$ in patients receiving concomitant nephrotoxic medications (16). In other words, considering concurrently administration of nephrotoxic agents is vital because it may lead to increase the toxicity of vancomycin synergistically, thus, adjusting the dose of vancomycin in these conditions is potentially required.

\section{Conclusion}

As a total rule, for optimal level of vancomycin during therapy, adequate through level of this drug should be maintained and below this level and also unexpected elevated peak level especially in old age and also in condition with concomitant other nephrotoxic drugs should be avoided. Therefore, routine monitoring of vancomycin in all conditions that high-flux membranes are applied, or other nephrotoxic agents are used should be planned. As an important point, in those conditions that low-flux membranes are used, monitoring the serum level of this drug should be also considered in older adults.

\section{Limitations of the study}

This study was conducted on a small proportion of dialysis individuals. We suggest a larger investigation on this aspect of renal failure patients.

\section{Acknowledgments}

The authors wish to thank Rasoul Akram Hospital Clinical Research Development Center, Iran University of Medical Sciences for technically supported the implementation of this project.

\section{Authors' contribution}

Conception and design of the study, or acquisition of data, or analysis and interpretation of data; NK. Drafting the article or revising it critically for important intellectual content; AF. Final approval of the version to be submitted; AJ and NK. 


\section{Conflicts of interest}

There were no points of conflicts to declare.

\section{Ethical considerations}

Ethical issues (including plagiarism, data fabrication, double publication) have been completely observed by the authors. The registration number of the thesis is 2052 .

\section{Funding/Support}

This research did not receive any specific grant from funding agencies in the public, commercial, or not for profit sectors.

\section{References}

1. Rybak M, Lomaestro B, Rotschafer JC, Moellering R Jr, Craig W, Billeter $\mathrm{M}$, et al. Therapeutic monitoring of vancomycin in adult patients: a consensus review of the American Society of Health-System Pharmacists, the Infectious Diseases Society of America, and the Society of Infectious Diseases Pharmacists. Am J Health Syst Pharm. 2009;66(1):82-98. doi: 10.2146/ajhp080434.

2. Matzke GR, McGory RW, Halstenson CE, Keane WF. Pharmacokinetics of vancomycin in patients with various degrees of renal function. Antimicrob Agents Chemother. 1984;25:433-7.

3. Launay-Vacher V, Izzedine H, Mercadal L, Deray G. Clinical review: Use of vancomycin in haemodialysis patients. Crit Care. 2002;6:313-6.

4. Pai AB, Pai MP. Vancomycin dosing in high flux hemodialysis: A limited-sampling algorithm. Am J Health Syst Pharm. 2004;61:1812-6.

5. Ariano RE, Fine A, Sitar DS, Rexrode S, Zelenitsky SA. Adequacy of a vancomycin dosing regimen in patients receiving high-flux hemodialysis. Am J Kidney Dis. 2005;46:681-7.

6. Pallotta KE, Manley HJ. Vancomycin use in patients requiring hemodialysis: A literature review. Semin Dial. 2008;21:63-70.

7. Ariano RE, Fine A, Sitar DS, Rexrode S, Zelenitsky SA.
Adequacy of a vancomycin dosing regimen in patients receiving high-flux hemodialysis. Am J Kidney Dis. 2005;46:681-7. doi: 10.1053/j.ajkd.2005.07.018.

8. Sakoulas G, Gold HS, Cohen RA, Venkataraman L, Moellering RC, Eliopoulos GM. Effects of prolonged vancomycin administration on methicillin-resistant Staphylococcus aureus (MRSA) in a patient with recurrent bacteraemia. J Antimicrob Chemother. 2006;57:699-704. doi: $10.1093 / \mathrm{jac} / \mathrm{dkl} 030$

9. Howden BP, Ward PB, Charles PG, Korman TM, Fuller A, $\mathrm{du}$ Cros P, et al. Treatment outcomes for serious infections caused by methicillin-resistant Staphylococcus aureus with reduced vancomycin susceptibility. Clin Infect Dis. 2004;38:521-8. doi: 10.1086/381202.

10. Zoer J, Schrander-van der Meer AM, van Dorp WT. Dosage recommendation of vancomycin during haemodialysis with highly permeable membranes. Pharm World Sci. 1997;19:191-6.

11. Lodise TP, Lomaestro BM, Graves J, Rodvold KA, Drusano GL. Larger vancomycin. Doses ( $\geq 4$ grams/day) are associated with an increased incidence of nephrotoxicity. Antimicrob Agents Chemother. 2008;52:1330-36. doi: 10.1128/AAC.01602-07

12. Taylor ME, Allon M. Practical vancomycin dosing in hemodialysis patients in the era of emerging vancomycin resistance: a single-center experience. Am J Kidney Dis. 2010;55:1163-5. doi: 10.1053/j.ajkd.2010.03.016

13. Barth RH, De Vincenzo N. Use of vancomycin in highflux hemodialysis: experience with 130 courses of therapy. Kidney Int. 1996;50:929-36.

14. Elyasi S, Khalili H. Vancomycin dosing nomograms targeting high serum trough levels in different populations: pros and cons. Eur J Clin Pharmacol. 2016;72:777-88. doi: 10.1007/s00228-016-2063-8.

15. Launay-Vacher V, Izzedine H, Mercadal L, Deray G. Clinical review: use of vancomycin in haemodialysis patients. Crit Care. 2002;6:313-6.

16. James CW, Gurk-Turner C. Recommendations for monitoring serum vancomycin concentrations. Proc (Bayl Univ Med Cent). 2001;14:189-90.

Copyright (c) 2019 The Author(s); Published by Nickan Research Institute. This is an open-access article distributed under the terms of the Creative Commons Attribution License (http://creativecommons.org/licenses/by/4.0), which permits unrestricted use, distribution, and reproduction in any medium, provided the original work is properly cited. 